\title{
The Future of Medicare Part D Drug Plans- Results From a Roundtable Discussion
}

\author{
Donald C. Balfour III, MD, FACP; Steven Evans, MD; Jeff Januska, PharmD; \\ Helen Y. Lee, PharmD, MBA; Sonya J. Lewis, RPh, MBA; Steve R. Nolan, PharmD; \\ Mark Noga, PharmD, RPh, CGP; Charles Stemple, DO, MBA; and Kishan Thapar, MD, MBBS
}

\begin{abstract}
BACKGROUND: The Medicare Prescription Drug, Improvement, and Modernization Act, signed into law in 2003, provided access to prescription drugs for elderly Americans. The Part $D$ benefit continues to evolve. Changes in plan designs, the impact of the doughnut hole on beneficiaries, and increased cost shifting have the potential to hamper the future of the Part $D$ benefit.

OBJECTIVE: To discuss factors that will likely have the most impact on the future of Medicare Part $D$ from a patient and payer perspective.

SUMMARY: The continued growth of the elderly population is expected to place an increasing burden on the services provided through Medicare. Given the current financial situation, it has been predicted that Medicare's Hospital Insurance Trust Fund will be depleted by 2019. To provide quality benefits and remain competitive, health plans are continually evaluating and redesigning their Part $D$ benefits. However, the current regulatory environment is preventing plans from offering innovative products and designs that could lower costs to beneficiaries. The growing number of beneficiaries hitting the doughnut hole is also becoming a concern for both beneficiaries and health plans. More beneficiaries are reaching the doughnut hole, and this has resulted in changes in beneficiary behaviors, including stopping medications, switching to alternative drug classes, and reducing medication use. Because of the increasing concerns about Medicare's sustainability, it is anticipated that the government may become more involved.

CONCLUSION: As the health care landscape continues to change, payers will be challenged to offer benefit designs that are affordable to elderly beneficiaries. For its part, the government must allow plans to design benefits that will improve the overall quality of care. Additionally, closer attention must be given to the growing number of beneficiaries hitting the doughnut hole and its potential adverse clinical and economic consequences.
\end{abstract}

J Manag Care Pharm. 2009;15(1)(Suppl S-a):S18-S21

Copyright@ 2009, Academy of Managed Care Pharmacy. All rights reserved.

\section{Authors}

DONALD BALFOUR III, MD, FACP, is President and Medical Director Sharp Rees-Stealy Medical Group, San Diego, California. STEVEN EVANS, MD, is Vice President of Medical Affairs and Pharmacy Director, Health Plan of Nevada, Las Vegas, Nevada. JEFF JANUSKA PharmD, is Director of Pharmacy Services, CenCal Health, Goleta, California. HELEN Y. LEE, PharmD, MBA, is Clinical Pharmacist, Clinical Services, CareFirst BlueCross BlueShield, Baltimore, Maryland. SONYA J. LEWIS, RPh, MBA, is Adjunct Professor of Pharmacy Practice, University of Colorado School of Pharmacy, Denver. STEVE R. NOLAN, PharmD, is Pharmacy Director, Rocky Mountain Health Plans, Fruita, Colorado. MARK NOGA, PharmD, RPh, CGP, is Regional Vice President, Clinical Pharmacy for Medicare, Coventry Health Care, Harrisburg, Pennsylvania. CHARLES STEMPLE, DO, $M B A$, is Regional Medical Director, Humana Healthcare of Ohio, Cincinnati,Ohio. KISHAN THAPAR, MD, MBBS, is Executive Director and Chief Executive Officer/Chief Medical Officer, ProMed HealthCare Administrators, Ontario, California.

AUTHOR CORRESPONDENCE: Donald Balfour III, MD, FACP, President and Medical Director, Sharp Rees-Stealy Medical Group, 2001 Fourth Ave., San Diego, California 92101-2600. Tel.: 619.446.1530; Fax: 619.223.4730; E-mail: donald.balfour@sharp.com
T he intent of Medicare Part D was to provide all elderly Americans with access to prescription medication. Despite its relative infancy, questions about the future of Medicare Part $\mathrm{D}$ are already being raised. The number of qualified elderly is increasing, and concerns about the added economic drain of this newer benefit on the already inadequately funded general Medicare benefit are increasingly heard. Plans are restructuring to adjust to changes in regulations and market pressures, often resulting in cost-shifting to the beneficiary. Furthermore, although Part D was designed to allow the private sector to administer the benefit, there is growing pressure for increased government involvement in the process.

\section{Economic Forecast Is Dismal}

The sustainability of Medicare from a financial standpoint has been the source of much debate. The increasing U.S. elderly population is expected to add financial strain to an already stretched system. ${ }^{1}$ Census Bureau data indicate that the United States is on the cusp of an elderly population explosion because of aging Baby Boomers. ${ }^{2}$ By 2030, the population of people aged $\geq 65$ years is expected to be twice as large as it was in the year 2000 (72 million vs. 35 million). Taking this projected increase into account, roughly 1 in 5 Americans will be elderly by 2030 (Figure 1).

Medicare costs in 2007 accounted for 3.2\% of the gross domestic product (GDP). The ratio of Medicare costs to the GDP is expected to rise sharply over the coming years and surpass the costs of Social Security by 2028 (Figure 2). ${ }^{3}$

According to the 2008 Social Security and Medicare Trustees reports, current financing arrangements are not sufficient to maintain the programs over the long term. ${ }^{3}$ The impending financial difficulty for Medicare will be realized before that of Social Security-Medicare's Hospital Insurance (HI) Trust Fund will be depleted by 2019 , followed by Social Security reserves in 2041. The HI Trust Fund pays for inpatient hospital and related care; the Medicare Supplementary Medical Insurance (SMI) Trust Fund pays for prescription benefits under Medicare Part D, and a separate part of this trust pays for physician and outpatient services. Social Security is funded by two additional trusts, OldAge and Survivors Insurance (OASI) and Disability Insurance (DI). These trusts are funded through taxes, premiums, and other dedicated revenues.

However, escalating health care costs require additional financing of these funds through general fund revenue because incomes from stagnate wages cannot keep pace with rising health care expenditures. ${ }^{3}$ It is anticipated that general revenue transfers to Medicare to help fund the program will account for 


\section{FIGURE 1 Older Americans Will Comprise 20\%}

of the Total Population By 2030a

Percent Aged 65 and Over of the Total Population: 2000 to 2050

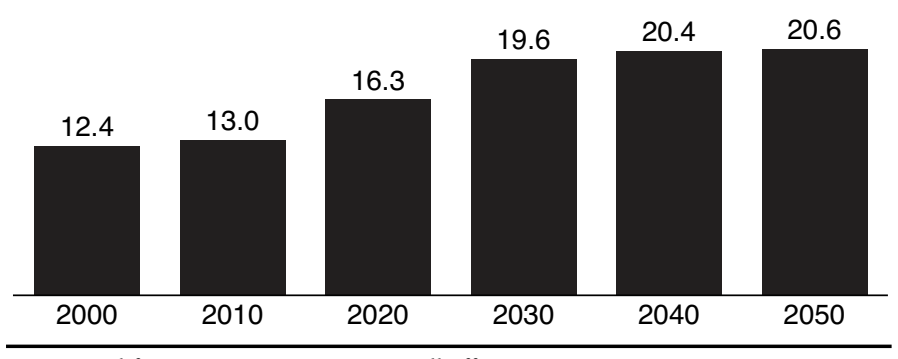

aExcerpted from He W, Sengupta M, Velkoff V, DeBarros K. U.S. Census Bureau, Current population reports (2005). ${ }^{2}$

Note: The reference population for these data is the resident population.

approximately half (45\%) of Medicare's outlays by 2014-this has helped fuel the current Medicare funding warning. ${ }^{3}$ This warning, signaling an inadequacy in the trust fund's dedicated financing, requires action from the President and Congress to examine the impact of Medicare on the federal budget in an expedited fashion.

The outlook for Part D financing is not quite as bleak as that for Medicare as a whole, since financing for the next year is automatically provided by law and is based on projected costs for the subsequent year. ${ }^{3}$ Federal general fund revenues are used to pay for $75 \%$ of Part D expenditures and the remaining costs are covered by the beneficiaries' monthly premium charges. ${ }^{3}$ Rapidly rising costs, however, are expected to affect Part D as well. These costs will be offset through increased cost shifting to the beneficiary-costs to beneficiaries are expected to grow and exceed the growth of both the economy and beneficiary incomes. ${ }^{3}$ This cost shifting will force the individual to assume more financial responsibility for prescription drug costs. ${ }^{4}$

\section{Evolution of Medicare Part D Plans}

Medicare Part D plan administrators will need to continually evaluate plan structure and reconfigure plan design to meet the challenges of increased costs and remain competitive. According to Summit participants, the current regulatory environment and Centers for Medicare and Medicaid (CMS) oversight of Part D programs has created some frustrations among plan sponsors and has limited the ability to offer innovative products and solutions.

Since the introduction of Medicare Part D in 2006, the prescription drug plan benefit has been available as either standalone prescription drug plans (PDPs) or Medicare Advantage prescription drug (MA-PD) plans. Plans must meet minimum requirements, and offerings vary based on benefit design, cost, gap coverage, formulary, and utilization management rules. The 2008 standard benefit includes a \$275 annual deductible, 25\%

\section{FIGURE 2 Projected Costs of Medicare Will} Surpass Social Security by $2028^{a}$

Social Security and Medicare Cost as a Percentage of GDP

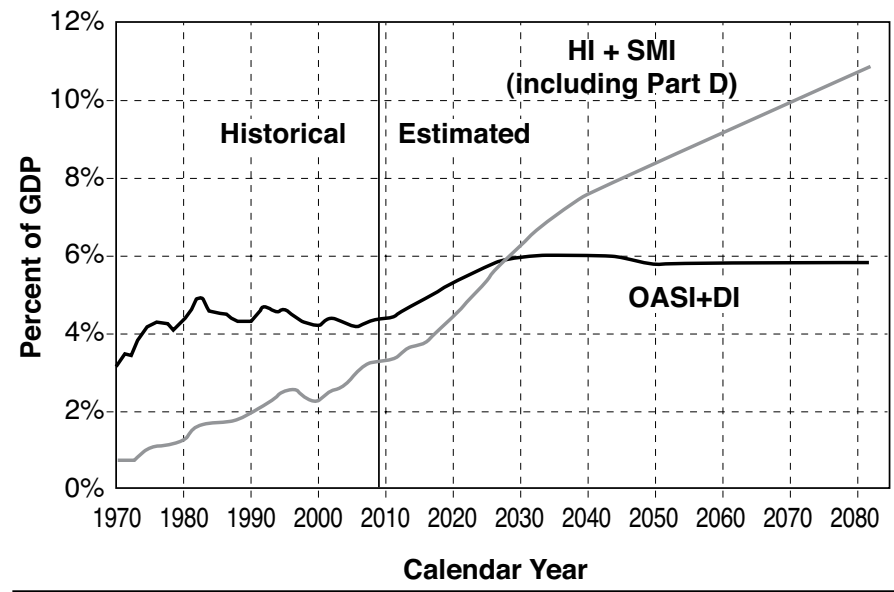

axcerpted from: A Summary of the 2008 Annual Reports: Social Security and Medicare Board of Trustees. ${ }^{3}$

$D I=$ Disability insurance $; G D=$ gross domestic product; $\mathrm{HI}=$ Hospital Insurance Trust Fund; OASI=Old-Age and Survivors Insurance; SMI = Supplementary Medical Insurance.

coinsurance up to an initial benefit threshold of $\$ 2,510$ in total drug costs, and a coverage gap where the beneficiary pays 100\% for the next $\$ 3,216$ in drug costs (the so-called doughnut hole). The catastrophic coverage threshold is met at $\$ 5,726$ in total costs ( $\$ 4,050$ in out-of-pocket spending), with the beneficiary paying 5\% co-insurance, the plan assuming 15\%, and Medicare bearing $80 \%$ of all further costs for the remainder of the calendar year. ${ }^{5}$ Currently, more than 25 million Medicare recipients are enrolled in Part D plans, with 70\% in a stand-alone PDP and 30\% in an MA-PD plan. ${ }^{6}$ The number of stand-alone PDPs increased from 2006 to 2007 but remained relatively stable in 2008. There has been some speculation that PDPs will phase out over time and are simply a transition product until beneficiaries convert to MA-PD plans. ${ }^{7}$ The authors concur with this assessment and predict the number of stand-alone PDPs will continue to decrease in the coming years.

Monthly premiums for drug plans differ based on the benefits offered. In general, premiums have increased each year and are in line with increased drugs costs. ${ }^{8}$ The average monthly premiums for PDPs in 2009 are expected to be approximately $\$ 28$ and about $\$ 17$ for MA-PD plans. These figures are actually lower than what was originally projected for $2009 .{ }^{8}$ Plans that offer some gap coverage tend to having higher monthly premiums. ${ }^{6}$ Plans offering the standard benefit often encourage generic drug use and less expensive therapeutic alternatives to keep beneficiaries from reaching the coverage gap.

Cost sharing has increased since the introduction of Medicare 
Part D, with many PDPs using tiered copayments; the amount of these copayments varies significantly between plans and is typically much lower for participants in larger, national PDPs. Currently, most PDPs also target high-cost medications and place them on a specialty tier as a cost-containment strategy. ${ }^{6}$ The number of plans implementing a specialty tier doubled from 2006 to $2008 .{ }^{6}$ With the emphasis on generic medication use, plans offer greater coverage for generic medications and shift the cost of branded and specialty medications to the beneficiary. Formulary and utilization management tools are increasingly used to manage drug costs and, depending on the benefit design, may increase the number of participants affected by the doughnut hole. Even with an open formulary, utilization management may restrict access to formulary drugs through step therapy, quantity limits, or prior authorization. ${ }^{6}$

\section{Growing Burden of the Doughnut Hole}

The doughnut hole, or gap in coverage, is a feature of Part D that increases the financial burden for many beneficiaries. The gap occurs when enrollees meet a set level of drug spending $(\$ 2,510$ in 2008) and remains in place until a designated out-of-pocket spend has occurred (e.g., in 2008, beneficiaries are responsible for $\$ 3,216$ while in the gap). ${ }^{5,6}$ For 2008 , this translated to $\$ 5,726$ in total drug spending before catastrophic benefits are in place. The value of the coverage gap is expected to double between 2007 and 2017, placing a significant financial burden on enrollees. ${ }^{9} \mathrm{~A}$ low-income subsidy (LIS) is available to assist beneficiaries who qualify; these individuals are not required to pay for medications in the coverage gap. ${ }^{9}$ In 2007, 26\% of non-LIS Part D enrollees reached the coverage gap. For those non-LIS beneficiaries with limited funds, the out-of-pocket expenses may hinder medication compliance. Documented changes in drug use for a representative sample of beneficiaries have occurred when enrollees reach the coverage gap (Figure 3). These changes include stopping medications, switching to an alternative drug class, and reducing medication use. ${ }^{9}$ As Part D plans continue to mature, careful attention to the doughnut hole's impact must be monitored to determine if the care of patients with serious chronic medical conditions is compromised.

\section{Potential for Increased Government Involvement}

While Part D has successfully increased medication access for millions of Americans, questions about cost continue to surface, and strategies to reduce and/or contain these costs remain at the forefront of Part D discussions. One of the biggest unanswered questions is whether negotiation of drug prices should remain in the private sector or move under government influence. ${ }^{10}$ While the government leveraged its purchasing power to obtain lower drug prices, price negotiation for Part D plans was left up to private plans because it was believed that market competition among plans would result in lower overall drug prices.

A report issued by the U.S. House of Representatives Committee

\section{FIGURE 3 Medication Drug Use Changes for Representative Medication Classes- Doughnut Holea}

Changes in Drug Use By Part D Enrollees Who Reached the Coverage Gap in 2007

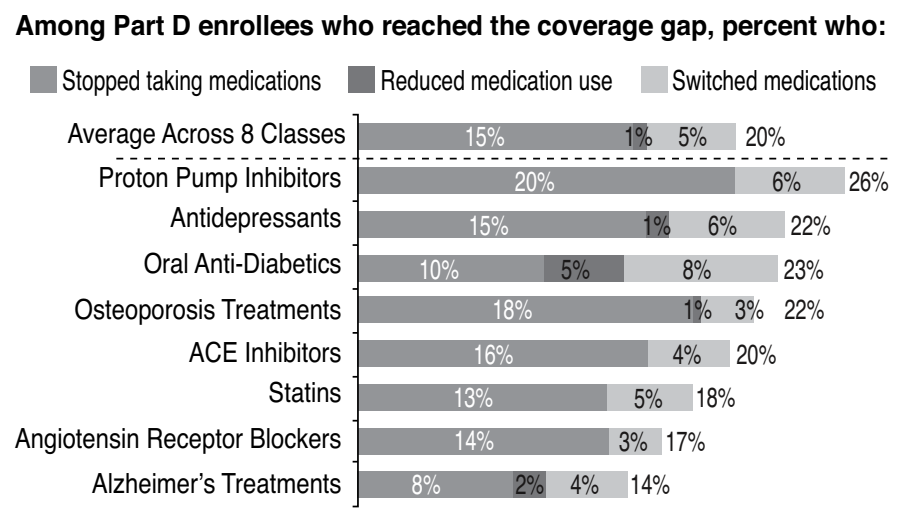

aExcerpted from "The Medicare Part D Coverage Gap: Costs and Consequences in 2007. The Henry J. Kaiser Family Foundation, August 2008. ${ }^{9}$ This information was reprinted with permission from the Henry J. Kaiser Family Foundation. The Kaiser Family Foundation is a non-profit private operating foundation, based in Menlo Park, California, dedicated to producing and communicating the best possible information, research, and analysis on health issues.

on Oversight and Government Reform in July 2008 addressed Medicare Part D pricing. Coverage for "dual eligibles"—elderly and disabled individuals qualifying for both Medicare and Medicaid-was a focus of the report, since Medicare Part D provides coverage for approximately 6 million dual eligible beneficiaries who, prior to the Part D rollout, received medications from Medicaid. These individuals account for at least $50 \%$ of drug spending through Part D and generally have lower incomes; 98\% of their drugs costs are covered by taxpayers through Part D.

Based on a review of confidential data from Part D's 10 largest insurers and Medicaid pricing from drug manufacturers, the committee found that prices paid for 97 of the top 100 prescription drugs used by dual beneficiaries were higher than prices paid for Medicaid. ${ }^{11}$ The prices for essential medications as defined by the CMS-protected list were especially high-rebates and discounts of only $7 \%$ were available to Part D insurers for 16 of the protected list drugs appearing on the top 100 list. Compared to Medicaid pricing for these same medications, the cost was $40 \%$ higher for Part D insurers. In its report, the committee noted that for the years 2006-2007, drug discounts offered by Medicare Part D were $\$ 3.7$ billion less than those offered by Medicaid ( $\$ 2.6$ billion vs. $\$ 6.3$ billion, respectively). ${ }^{11}$ This difference results from rebates that Medicaid had negotiated with manufacturers. The report concludes that a savings for dual eligibles of $\$ 86$ billion over the next 10 years could be realized if Part D insurers were 
given price discounts equal to those of Medicaid. ${ }^{11}$

As discussed in the section, "Current Management of Part D Benefits," (see page S4) CMS regulations regarding formulary coverage may have impeded the ability of the plans to negotiate the level of cost savings traditionally secured for commercially covered lives. Furthermore, while the potential for cost savings that could be realized from government-led Medicare price negotiations may be enticing, there is no guarantee that this level of savings will actually come to fruition. In a recent congressional report, the potential implications of federal price negotiations were reviewed. ${ }^{12}$ Concerns about centralized negotiations include the restriction of formulary choice; for example the number of drugs in the Veterans' Affairs formulary is considered much more restrictive than the formularies in private plans. The effect of government pricing on pharmaceutical manufacturers and their ability to continue funding research and development has also been raised. Negotiated prices that are passed to plans may decrease the ability of plans to remain competitive, resulting in a reduced number of available plans. Another consequence of set drug prices for the Medicare population would be the effect of this pricing on other markets-especially the pricing of medications for non-Medicare recipients. There is a possibility that Medicare beneficiaries will bear the brunt of federal negotiations as higher costs are passed to these individuals.

Strong arguments against government influence have been put forth by the Academy of Managed Care Pharmacy (AMCP). ${ }^{13-15}$ AMCP opposes government interference and supports a competitive model for the provision of Medicare Part D benefits. AMCP raises concerns about the separation of formulary development and pricing. In its official position on this issue, AMCP states, "Authorizing the federal government to negotiate the purchase price of drugs under the Medicare Part D program would inappropriately separate price negotiation from the formulary development process."14 AMCP further states, "Mandatory requirements imposed by the government could weaken the program, disadvantage beneficiaries, and threaten the long term financial success of the benefit."15

\section{Conclusion}

Medicare Part D will continue to evolve as the landscape of health care changes. If Medicare is going to remain a viable health benefit in the United States, funding issues need to be addressed, and a solution that prevents the exhaustion of the trust funds must be enacted. The structure of the plans will also continue to evolve. It is too early in the Part D story to determine how the drug plan benefit will play out and whether PDPs will phase out or if the number of plans will diminish in response to increased regulation and oversight. If the coverage gap remains an active concern and cost shifting to the patient continues, the effect of the increasing economic burden on beneficiaries will require a closer look. Greater government involvement in the negotiation of drug pricing may be on the horizon.

\section{DISCLOSURES}

This roundtable seminar was funded by Takeda Pharmaceuticals North America, Inc. Steve R. Nolan is an advisory board member for Takeda Pharmaceuticals North America, Inc. Kishan Thapar is a member of the speakers' bureau and receives speaking fees from Takeda Pharmaeuticals North America, Inc.

Medical writers Charlotte A. Kenreigh, Linda Timm Wagner, and Dennis Bloshuk, Editor, Strategic Healthcare Alliance, contributed the literature search to this supplement, as well as the writing and revision of the manuscripts.

\section{REFERENCES}

1. Henry J. Kaiser Family Foundation. Medicare: a primer. March 2007. Available at: www.kff.org/medicare/upload/7615.pdf. Accessed December 18, 2008.

2. He W, Sengupta M, Velkoff V, DeBarros K. U.S. Census Bureau, Current population reports, P23-209, 65+ in the United States: 2005. Washington, DC: U.S. Government Printing Office; 2005.

3. Social Security Administration. A Summary of the 2008 Annual Reports: Social Security and Medicare Board of Trustees. Available at: www.ssa.gov/ OACT/TRSUM/trsummary.html. Accessed September 22, 2008.

4. National Coalition on Health Care. Facts on Health Care Costs. www.nchc. org/documents/cost_fact_sheet_2008.pdf. Accessed December 18, 2008.

5. Hoadley J, Hargrave E, Merrell K, Cubanski J, Neuman T. Medicare Part D 2008 data spotlight: benefit design. Henry J. Kaiser Family Foundation. Available at: www.kff.org/medicare/upload/7713.pdf. Accessed September 22, 2008.

6. Hoadley J, Hargrave E, Cubanski J, Neuman T. Medicare prescription drug plans in 2008 and key changes since 2006: summary of findings. Henry J. Kaiser Family Foundation. Available at: www.kff.org/medicare/ upload/7762.pdf. Accessed September 22, 2008.

7. Carroll J. Managed Medicare revitalized: feel-good plan of the decade. Manag Care. 2006;15(9):22-24, 26-28, 33. Available at: www.managedcaremag. com/archives/0609/0609.medicare.html. Accessed December 18, 2008.

8. Centers for Medicare \& Medicaid Services. Press Releases. Lower Medicare Part D costs than expected in 2009. Available at: www.cms.hhs.gov/apps/ media/press/release. asp? Counter $=3240 \&$ intNumPerPage $=10 \&$ checkDate $=\& c h$ eckKey $=\&$ srchType $=1 \&$ numDays $=3500 \&$ srchOpt $=0 \&$ srchData $=\&$ keywordTy pe $=$ All \&chkNewsType $=1 \% 2 \mathrm{C}+2 \% 2 \mathrm{C}+3 \% 2 \mathrm{C}+4 \% 2 \mathrm{C}+5 \&$ intPage $=\&$ showAll $=\& p$ Year $=\& y e a r=\& d e s c=\& c b o O r d e r=$ date. Accessed September 22, 2008.

9. Hoadley J, Hargrave E, Cubanski J, Neuman T. The Medicare Part D coverage gap: Costs and consequences in 2007. Henry J. Kaiser Family Foundation. Available at: www.kff.org/medicare/upload/7811.pdf. Accessed September 22, 2008

10. Frank R, Newhouse J. Should drug prices be negotiated under Part D of Medicare? And if so, how? Health Aff (Millwood). 2008;27(1):33-43.

11. United States House of Representatives. Committee on Oversight and Government Reform Majority Staff. Medicare Part D: pricing and manufacturer windfalls. Available at: www.oversight.house.gov/documents/20080724101850.pdf. Accessed September 23, 2008.

12. Hahn J. CRS Report for Congress. Federal drug price negotiation: implications for Medicare Part D. Available at: www.policyarchive.org/bitstream/handle/10207/3053/RL33782_20070105.pdf?sequence=1. Accessed October 9, 2008.

13. Academy of Managed Care Pharmacy. Future of Medicare Part D: Competitive Model. http://69.0.204.76/amcp.ark?p=AA5B4A21. Accessed September 23, 2008.

14. Academy of Managed Care Pharmacy. Future of Medicare Part D: Reliance on Medicare Part D plan sponsors to negotiate prices with pharmaceutical manufacturers. Available at: http://69.0.204.76/amcp. ark? $=$ =AA5B4A21. Accessed September 23, 2008.

15. Academy of Managed Care Pharmacy. Future of Medicare Part D: Formularies offered by Part D insurance plans provide patients with access to effective, safe, and affordable medications. Available at: http://69.0.204.76/ amcp.ark?p=AA5B4A21. Accessed September 23, 2008. 